\title{
Indian Politics: A New Threshold
}

\author{
Prof. (Dr.) Shilpa Khatri Babbar ${ }^{1}$
}

\begin{abstract}
Since 2013, there have been apparent changes in the Indian political structure calling for a maternal dependence of the political leaders on the larger society for their sustenance. People have become aware of the power of and in, their vote. The credit of verstehen-driven politics goes to ArvindKejriwal, the leader of a newly formed political party, AAP. This paper, offers an insight into his leadership and the associated party politics which shall leave its imprints on the upcoming LokSabha elections in India.
\end{abstract}

Keywords: Aamadmi, direct democracy, Jan Lokpal bill, reshwat, verstehen.

\section{Introduction}

This paper is about an Indianpolitical leader, ArvindKejriwal, who initiated a new era of politics, attaching subjective meanings to his public actions in their mutual orientations. Unwilling to commit himself either to a materialistic or an idealistic interpretation of politics, his ultimate unit of analysis isclaimed to be the concrete acting person, the common man, popularly known as the aamadmi.

Politics in India had never been a part of the everyday life of the common man. At the National level, it was a battle primarily between two major National Parties, BharatiyaJanta Party (BJP) and Congress. The battle was fought either on grounds of caste (both privileges and dis-privileges) or religion or as a matter of 'traditional' authority structure manifestly or latently put across in their 'popularistic manifestoes'. The fight was always on elaborately decorated stages, conducted with huge pomp and show supported with a war of words, allegations and counter-allegations, projected as ideological deficiencies, inefficient actions and un-kept commitments.

\section{New Era of politics}

In the 2013 Delhi Legislative Assembly elections, politics was brought down from the inaccessible elaborate stages to everyday streets, from fashionable leaders to a common man, from the upper class comforts to a middle class belongingness. Agitations, demonstrations and actions, both legitimate as well as illegitimate, constitutional as well as unconstitutional were seen at a large scale. Politics was reduced to actions of participating individuals, who are understandable and not mere abstract conceptual entities. The common man in it is projected as the upper limit and sole carrier of politically meaningful conduct. The leader of this new era of politics, ArvindKejriwal, redefined politics by locating himself within the wider public and doing away with the 'heaven of the political domain' mentality, wherein the control was exercised from above, sometimes even extraneous sources but never from within.

The new political knowledge acquired was projected as knowledge acquired through experience and understanding, attained through an internal process primarily based on keeping the fingers on the pulse of masses. Human actors and their cultural creations are endowed with meanings and the only way in which humanistic political leader can accomplish this is through re-experiencing the meanings carried by historical actors or cultural objects, who in the current context is the aamadmi(common man). In his treatment of historical knowledge, Heinrich Rickert in tune with the Kantian heritage insisted that the act of knowing transforms the object of knowledge ${ }^{2}$. This seems to be the source of confidence which carriedKejriwal to initiate his political journey. In his work titled 'Swaraj' ${ }^{3}$ he has highlighted the various success stories of communities who have taken upon themselves the ownership of initiating a road map to their collective destinies.

In pursuing his belief in self-governance, Kejriwalhas argued for empowerment of Gram Sabhas to appoint as well as to suspend all government employees, thereby enhancing their accountability to the village. Government funds, "servants", laws and actions that go towards the making of laws and natural resources, he argues, need to be brought under the control of the common man, through the Gram Sabhas.

\footnotetext{
${ }^{1}$ Vivekananda Law School, Vivekananda Institute of Professional Studies (Affiliated to Guru Gobind Singh Indraprastha University), Delhi, India.

${ }^{2}$ Ronald Fletcher, The making of sociology: a study of sociological theory (New York: Charles Scribner's Sons, 1971).

${ }^{3}$ ArvindKejriwal, Swaraj(Harper Collins, 2012)

${ }^{4}$ The term has been used loosely for all government employees.
} 


\section{Effectual, Charismatic or Rational Action?}

Kejriwal posited himself as the untainted outsider, the man from nowhere, the truth teller, the unabashed and unafraid angry Indian, without a well-chronicled family history, bashing away at the culture of privilege. It is in the midst of such shades of protest, frustration and also determination to bring about a radical change that the new era of politics dawned, encapsulatingimages of affectivity, charisma as well as legality.

Kejriwal is the eldest amongst the three siblings and was born in Siwani, a city in Haryana on Janamasthami; the day when Lord Krishna was born.Mythologically speaking, Lord Krishna is the eighth incarnation of Lord Vishnu and is popular for his charismatic personality and character in both the worlds. He is regarded as the epitome of guidance, friendship, love and righteousness. This belief has given the 'affective' edge to the persona of Kejriwal and is popularly seen by his family and followers as "today's Krishna" armed with the sudarshan chakra ${ }^{5}$ to streamline positive changes.

He took up Mechanical Engineering at IIT, Kharagpur and as the Governor of the Hindi Drama Society in his final year, learnt the skill of holding the crowds. Hedexterously uses this skill today in his speeches soaked in determined action. In fact, his close batch mates voice that a lot of his sensitivity and urge for change, shaped up at IIT.

Till 1992, he worked with the Tata Steel Company, Jamshedpur, from where he resigned to appear for the Civil Services Examination. He qualified for the Indian Revenue Service (IRS) in 1995. In 1999 he took a leave for two years to crack Indian Administrative Examinations (IAS) but once again qualified for IRS.He rejoined in 2003 and later in 2006resigned as a Joint Commissioner in the Income Tax Department. In 2000, he started an NGO called Parivartan (change), with an objective to take India out of the "reshwat" (graft) which has been ingrained in the Indian system. The first public redressal of grievances called "Jansunwai", initiated by Parivartan was on issues pertaining to irregularities in the Public Distribution System. The decision to resign and the motivation to bring about societal transformation was the first formal step towards a new political threshold, anchored in emotionally charged altruism.

In 2005, hiscampaign to introduce the Right to Information Act in India, earned himthe Ramon Magsaysay Award in 2006.

The grasping of subjective meaning of an activity is facilitated through empathy and a relieving of the experience. It is in this context that the demand for a Lokpal or ombudsman to investigate and prosecute corrupt officers was the headline of the Anti-Corruption movement designed by Kejriwal in 2012. This was fronted by his former mentor, Anna Hazare. The disagreement between Kejriwal and Anna (as he is popularly called) grew out of Kejriwal's decision to form a political party, labelled as 'AamAdmi Party' (AAP), launched in October, 2012, which he justified as the only way to sanitise the Indian system fully soaked in reshwat. This was soon followed by a shift from the silent satyagrahas accompanied with sporadic hunger protests, to loud street agitations whichsoon became charismatically magnetic, leading to the rational-legal chair of power at Humayun Road, Delhi.

In fact before the launch of AAP, Kejriwal was challenged by prominent political leaders to stage himself in the "political complexities and struggles" and show the country the changes he popularly desired. His pronouncement to form a party seems to be cognisant and enthused by an inherent urge and fortitude to show that desirable changes are always possible.

Though in modern society, the efficient application of means to ends has become predominant and has replaced other springs of social action; but in case of the new-fangled Indian political domain, though the end is predominant, but the ambiguity of means towards it, is apparent. The glimpses of AAP's governance (discussed ahead) seem to be an ideal type governance, a utopia, at least a number of steps away from the concrete reality, if not far away. But then there can never be a full empirical embodiment of perfect governance. This governance can indeed be used as a conceptual device with which the real development can be measured as it is essentially constructed out of certain elements of reality.

\section{Delhi Legislative Assemble Elections}

The results of the election to Delhi legislative Assembly came as an utter surprise not merely to those already in power but also to the new political initiators themselves and also to the public at large. The political crisis was not hidden and so was not the uncertainty that followed the election where in no party could win the majority. But the spring of utter surprise was that the leader of a virgin partycame up with a huge bang, defeating the three-time Chief MinisterSheila Dixit, in her own constituency of New Delhi and that also in Kejriwal's first election, by 22,000 votes.

With neither the age at his benefit(average age of cabinet in India being 65 years ${ }^{6}$ while Kejriwal is only 45 years old) nor anypolitical backup nor any committees formed as empathisers to grievance redressal,

${ }^{5}$ A disc given by Lord Shiva to defeat demons.

${ }^{6}$ Age and Leadership: Gerontocracy, The Economist Online, February $15^{\text {th }}, 2011$. 
Kejriwalwas sworn-in on $28^{\text {th }}$ December, 2013 as the Chief Minister, in fact, the youngest Chief Minister of Delhi. Unlike his predecessors, as a tribute to acknowledge the role of the public in his victory, he decided to use public transport and rode a metro to the RamlilaMaidan, a public park, to take oath as the Chief Minister.

Before the official results, neither did the supporters of popular or rather conventional parties nor the political bosses felt the need to defend or guard their positions. In fact, they wrote off AAP as a mere "group of activists", lacking experience, vision and funding. Attached to the notion of "group of activists" was the presumed impression about the group being not well organized and therefore politically inconsequential.

But within days, AAP sought online donations and posted their records on its website. Using tactics popularized by the US President, Barrack Obama, the party raised nearly 20 crores (\$3.2 million) through small donations, with supporters' names listed on the website. This accountability sparked huge support. An army of volunteers pounded the Delhi pavements day and night, brandishing the party symbol, a broom, declaring to cleanse the polity of venality and to restore citizens' rights. Their objective was so close to the heart of the masses and their strategy was so well carved out that AAP soon became a "necessary evil", if not a fish bone for the Delhi Political scenario.

Since no party won the majority, AAP was offered support by the Congress Party to form a government. In a display of citizenship politics, the leaders of AAP, consulted the people of the city and agreed to lead the Delhi government with external support from Congress. This was the beginning of the 49 day journey of AAP as a minority government in Delhi.

With the larger objective of doing away with corruption and the demand for Lokpalas an immediate step towards it, one can see that the goal was rationally designed. The deep trench in which Indiais caught created by varied but apparent forms of corruption made AAP an affective choice for all. The only fear was whether the seemingly common man's party would lose its compassion towards the common man and enjoy the various manifestations of power? But the risk was worth taking and so justified are the graphically unbelievable curves of poll victory and loses.

\section{Direct Democracy}

The idea ofreducing politics to the actions of participating individuals and taking the larger public into confidence is derived from the influence exercised by Switzerland on Kejriwal. In 'Swaraj', he has projected Switzerland, as one of the few democratic paradises on the globe. He substantiates his thought by the argument that if 50,000 people, in Switzerland, sign a demand for change in legislation, the Swiss government has to put forth a bill in the parliament and if 1,00, 000 people send in a similar representation, then the Swiss government has to put forth a bill for amending the constitution.

This idea of participatory politics was taken literally and stretched too far when Kejriwal decided to hold "Janta Durbar" (public courts) to address the grievances of the masses. On $11^{\text {th }}$ January, 2013, along with his entire Cabinet, he sat in front of the Delhi Secretariat justifying it by labelling it as a duty of every government to resolve grievances. He saw public grievance as a mere symptom of a disease which lay somewhere else. The opening of the VIP gates of the Secretariat for the aamadmi - a promise that AAP had made in its manifesto - resulted in his first janta durbarwhich ended up in chaos. The security officials were outnumbered by the larger - than - expected crowd because of which Kejriwal had to exist mid-way.

His own argument against the applicability of uniform norms and policies, insensitive to the specificity of a region, community or country seemed to have been overlooked. The examples of the Swiss Parliament reflecting the will of the people; the preparation of budget in the streets of Porto Agrele, a small town in Brazil; the weekly meeting of the people of Middle Town to discuss their problems and to take collective decisions seem to have ensnaredKejriwal and affectively forced him to apply it in the Indian Context. Apart from the objective issues such as geography, population and cultural factors, the issue of political maturity especially amongst masses, which is highly subjective, was disregarded. Moreover the concept ofjanta durbar goes against the basic grain of decentralization for in it people are invited to converge at one central place to register all types of complaints.

Further, the idea of direct democracy wherein people get an opportunity to participate in power, has an inherent assumption that people are always right. This is a highly romanticized notion. AshutoshVarshney ${ }^{7}$ has rightly pointed out that though democracies must represent popular wishes but one must be alert about the fact that democracy is also a battle against popular prejudices and a fight for higher principles.

\section{Kejriwal: A Historical Causality or Sociological Causality}

Historical causality determines the unique circumstances that have given rise to an event while sociological causality assumes the establishment of a regular relationship between two phenomena, which need not take the form 'A makes B inevitable' but may take the form, 'A is more or less favourable to B'.

AshutoshVarshney, Battles half won: India's improbable democracy (Penguin India, 2013) 
The case of Kejriwal compels us to blur the distinction between historical and sociological causality. Society is as a delicate balance of multiple opposing forces, where a revolution or even a heroic leader can succeed in throwing the total balance in favour of a particular outcome. The dawn of the new era of politics is a like a Pandora's Box opened with valour by the charismatic AAP. The charisma lay in the reachable goals and the verstehen (subjective understanding) deployed. A lot of this charisma is linked to the ordinary everyday decisions like those associated with water, electricity, etc., which had been largely ignored and now taken up by Kejriwal. This has enabled him to draw a connectwith the masses and maintain it too. The urban middle class in India has always felt politically disempowered as the powerful cabal that ruled the country has always seen the rural vote as critical for its survival. Despite constituting 32 percent of the total population, they have been invisible in the political agendas. These urban middle class votes, have been rediscovered (first by NarendraModi, leader of BJP and now) by AAP in this new era of Indian politics.

Kejriwal has been quite successful in projecting himself as a reformer who has apparently sacrificed his professional privileges for the nation.He has successfully earned amongst a reasonable section of people, especially the subaltern classes, an image of a messiah, who has taken up the crusade of cleansing the 'Augean stables' of politics. This resonates clearly in his farewell speech wherein he posited himself as a willing servant of the larger humanity, 'ready to even give up his life as a price to fight out corruption'. The maturity with which he has decided on his Anti-Corruption objective and the perfection of involvement with which he has carved out the agitational culture of his political group, seems to have empowered him to comfortably sweep under the carpet his party's immature reactions/actions too.

\section{Governance: Confirmative or non-confirmative}

Despite the apparently positive intention, the 49 days governance has witnessed strains of normatively destructive behavioural patterns. These definitely cannot be labelled as 'actions' for manifestly they neither qualify as well thought out nor were consciously carried out nor seem to have been purposeful. How meaningful they are is for the reader to decide.

The midnight raid on Ugandan women, led by Kejriwal's team member, SomanathBharti, who was then the Law Minister, created a huge uproar with regard to issues such as gender and race sensitivity. His misuse of the Rational - Legal Authority in trying to bully the police team into arresting the women without either a warrant or evidence, created a great deal of disenchantment, if not disconnect, amongst at least the subaltern classes. To further add to the distances was Kejriwal's call for dharna (sit-ins) to support Bharti and the defiance of police orders, urging the capital to join on a 10-day protest.

In wake of his heroism, he boasted of himself as an "anarchist" and unleashed a populist image of himself, which after this, is under the risk of becoming a little tarnished. This dragged the governance to pure affectual action. The paradigm of Kejriwal's governance is quite paradoxical. Despite being fashioned on a design laid down by the Father of the Nation Mahatma Gandhi, which would have made it quite predictable, has indeed proved otherwise.

Using a popular talk show as a forum, another prominent supporter of AAP, PrashantBhushan, sparked a controversy by talking of a referendum in Jammu and Kashmir to decide whether the people wanted the army to handle internal security or not. No doubt that this statement was in keeping with their collectively nurtured idea of participatory democracy but it definitely is one of the very sensitive issues, to be dragged on streets. Kejriwal's continuous silence with regard to the growing indiscipline caused during AAP's governance is also apparent in choosing Jarnail Singh to contest the LokSabha elections, who was a journalist with a National Daily and had hurled a shoe at the Union Minister P. Chidambaram in 2009 in protest against his remarks on the clean chit to the accused Congress leaders, in the 1984 anti-Sikh riots. Though unaccountability of representatives is indeed the root cause of Indian politics but the masses felt that this cannot be fought against with arrogance or indiscipline.

In maintaining the 'spirit of modern rational capitalism' intertwined with ethics and morality and in opposition to the traditional amoral capitalism, a First Information Report was filed against the Reliance Chairman MukeshAmbani, Petroleum Minister VeerappaMoily, MurliDeora, who was the Petroleum Minister between 2006 and 2011 and other policy makers over a 2007 decision to hike gas prices to four dollars a unit. It also charges the Centre with giving approval to Reliance's plan of quadrupling their expenditure from \$2.2billion to over \$8billion, when their production target had only doubled, in just 2 years.

Kejriwal alleged that the Central Government and MukeshAmbani colluded to inflate the gas prices produced from the D-6 block off the Eastern Coast which is being operated by the Reliance. This indeed has stained the clear stream of cash flow from big pressure houses to tainted politics.

Kejriwal's oratorical skills and disdain for the norms of not making personal charges have indeed drawn large crowds. There is no absolutely 'objective' scientific analysis of culture or of 'social phenomena' or administration. What is considered "worthy to be known" depends upon the perspective of the inquiring scholar or leader. What particular problem attracts a leader or scholar, and what level of explanation is sought, depends 
on the values and interests of the investigator or leader. The choice of the problem, in this case, 'corruption', is "value relevant". Value element inevitably enters into the selection of the problem, which the leader chooses to attack. There is no scientific criterion for selection of topics. Ethical neutrality implies that once the social scientist has chosen his problem in terms of its relevance to his values, he must hold values in abeyance while he follows the guidelines his data reveal. It is of utmost importance that men in politics should be governed by the ethos of politics in their role either as politicians or administrators or for that matter even as citizens.

But then all science involves selection as well as abstraction. No scientific system is ever capable of reproducing all concrete reality, nor can any conceptual apparatus ever do full justice to the infinite diversity of particular phenomena.

\section{Aapnomics 8}

Though Kejriwalsees fixing politics as a precursor to an assuredlysuccessful working of economic policies but his aapnomics agrees with the fact that it is only within the framework of a rationalized economy that an active individual can weigh utility and costs in a rational manner.He sees people in business as a source of generating employment for the nation as well as a source of wealth creation. He justified his decision to audit power companies and the tirade against Reliance Industries as being against crony capitalism and not capitalism per say. Rejecting the image of a socialist in making, he firmly believes that all businesses in the country should be privately owned. He seesinspector raj andlicence Raj as"extortionist" systems encouraging malpractices and rishwat. He saw the private sector as the ultimate job creator while at the same time did not view privatization as the solution to all related issues. He argued that all policies should be made on a proactive basis that encouraged, rather than discouraged business. It is in this vein that his cabinet overturned the previous government's decision on FDI in retail.

\section{A Status Group: AAP}

Whether this shall earn AAP, in general and Kejriwal in particular, higher credentials, shall be decided by the ensuing elections but any authority, in all its manifestations is not merely an attribute of the leader alone but rather primarily a characteristic of the relation between leaders and followers. The notion of charisma embanks on the fact that the leader derives his role from the belief his followers have about his mission. The political party launched by Kejriwal has been like a "status group" in the sense of a cobbled community held together by notions of life-styles and by social esteem and honour accorded to it by the masses. Kejriwal has been extremely cautious in not letting go of the image of an aamadmi, be that be in terms of his 'modest' clothes, grounded display of reachable dreams in his speech or his gifted blue Wagon-R, without any beacon and hooters which was often seen waiting at traffic signals, instead of whizzing through, as has usually been the case of the political leaders on Delhi roads.

Linked with this idea of a status-group, are the expectations of restrictions on social intercourse with those not belonging to the circle and assumed social distance towards inferiors, in this case those with unmatched mind-sets and tarnished selves. This to a great extend justifies Kejriwal's skewed outlook, comprising left-of-centre economics (no to foreign investment in retail) and right-of-centre sociology (yes to khappanchayats, community courts in Haryana's villages).

When it came to the passing of the Jan Lokpal Bill in the assembly, obstinacy of Kejriwal's leadership compelled chopping off already much compromised links with the party of 'dynasty leadership'. It raised a fresh controversy questioning the very need to have the chair of the governor. The chair was seen by AAP, as a vestigial remnant of the British era, an unnecessary adjunct in the current political scenario constantly reminding the Indians of the need to submit to the political patriarchs. The background to this was the 'rule-bound procedure' highlighted by the Lieutenant Governor Najeeb Jung whereby the Jan Lokpal Bill could not be passed by the assembly unless it was first sent to him for consent and then approved by the Home Ministry. The issue which came to be debated was whether the government of Delhi should be subjected to 'Home Ministry dictates or discretionary orders'. It was argued by some that these orders should not be so powerful so as to over-rule a law passed by elected representatives of the state while the others felt it would be unconstitutional to go ahead with it.

\section{Conclusion}

Providing 700 litres of free water for households with regular water connection along with 50 percent of power subsidy for those consuming up to 400 units is indeed a product of verstehenand has earned immense trust and confidence amongst the masses for Kejriwal. Anew political process fed with accountability and collective thinking has been initiated but the uphill task is to pave way in the 'existent system'. Having shaped a movement into a party with Jan LokpalBill as its rallying point, the manner in which the Bill was put across by

${ }^{8}$ Popular term used forKejriwal's views on the economic policies. 
AAP, did not appear to be an honest attempt to clear it. There is indeed a great deal of polishing required in their political pedagogy. Not merely corruption but also indiscipline, disrespect and arrogance towards the laws, societal responsibility, constitution and all that is respectfully Indian, has to be generated. Fighting the battle with similar kind of weapons would only call for a genetic mutilation of the society.

Creation of Telangana, special status for Seemandhara, demand for Bodoland, demand for special status for Bihar, all these are political strategies of distancing citizens from each other. They are strategic tools behind vote bank and unethical politics. An unfortunate era of aggression is seeping in India, in particular and the world in general, where individual egos are overriding and the masses are unable to accommodate and integrate with the wider society.

The coming 2014 LokSabha elections are elusive primarily because of its predictable unpredictability. The rise of the regional parties reflects the permeation of economic and political democracy in India. Regional leaders like Naveen Patnaik, Nitish Kumar, etc. have reshaped the vertical Indian political power centre giving it horizontal dimensions. This apparently does not seem to be a positive picture for Kejriwal.

Upcoming elections are significant because of the gigantic numbers of voters. Another factor of significance lies in terms of leadership, where individuals have taken over parties. Whether the vote for Kejriwal was a vote for hope or a bet on the vision of a golden future or a protest vote is still in dark. The role of media in these elections is very crucial for they played a significant role in bringing alive the aamadmi who was silenced by the rule of the khasadmi (the privileged). Another crucial element in 2014 elections is that following the amendment of the Representation of the People Bill in 2010, the citizens of India, living abroad, were given a chance to register as voters. They can cast their vote provided they don't hold citizenship of any other country.

This NRI participation is quite in tune with AAP's policy of 'people's participation' at all levels. From Anjali Damania, a pathologist in Mumbai to Christina Samy, a trained mid-wife from Karur (Tamil Naidu), the common strand in this assortment of AAP membership is their ideological territoriality in the civil society. Other than occasional flirtation with politics at the school or college level, none of the members of AAP have ever been affiliated with a formal political party; yet they have indeed been extremely successful in establishing a connect with the hearts of the masses. Even if the coming polls may not be able to certify AAPs political victory, the Indian socio-political history shall not be able to disregard them. Amidst the name of Gandhi, Jayaprakash Narayan and V.P. Singh shall be added ArvindKejriwal, the leader of a new political era.

After the end of the 49 days of his Chief Ministership, the goal is still there, the intention to clean up "a corrupt system", though the means have changed. Back to the streets, the agitational politics kicked off in the form of a 'JhaadhuChalaoYatra' across 24 states on $15^{\text {th }}$ February, 2014 building itself for the LokSabha elections, 2014.

\section{Acknowledgements}

Author is highly grateful to Mr. Vishrut Rai Khatri, who along with his team, untiringly assisted in writing this article.

\footnotetext{
[1] ArvindKejriwal, Swaraj(Harper Collins, 2012)
}

\section{References}

[2] AnjanChakrabarti and AnupDhar, India and the politics of corruption, Philosophers for Change, philosophersforchange.org, February 4, 2014.

[3] Ronald Fletcher,The making of sociology: a study of sociological theory (New York: Charles Scribner's Sons, 1971)

[4] Age and Leadership: Gerontocracy, The Economist Online, February 15 ${ }^{\text {th }}, 2011$

[5] AshutoshVarshney, Battles half won: India's improbable democracy (Penguin India, 2013) 